\title{
Polyester films obtained by non-catalyzed melt-condensation polymerization of aleuritic (9,10,16-trihydroxyhexadecanoic) acid in air.
}

José Jesús Benítez ${ }^{1 *}$, José Alejandro Heredia-Guerrero², Susana Guzmán-Puyol², Eva Domínguez $^{3}$ and Antonio Heredia ${ }^{4}$.

\author{
${ }^{1}$ Instituto de Ciencia de Materiales de Sevilla (ICMS). Centro mixto CSIC-Universidad de \\ Sevilla, Avda. Americo Vespuccio 49, Isla de la Cartuja, E-41092 Sevilla (Spain). \\ ${ }^{2}$ Nanophysics, Istituto Italiano di Tecnologia (IIT), 16163 Genoa (Italy). \\ ${ }^{3}$ Instituto de Hortofruticultura Subtropical y Mediterránea (IHSM) La Mayora. Universidad de \\ Málaga-CSIC, Algarrobo-Costa, E-29750 Málaga (Spain). \\ ${ }^{4}$ Departamento de Biología Molecular y Bioquímica, IHSM La Mayora. UMA-CSIC. \\ Universidad de Málaga, E-29071 Málaga (Spain).
}

*Corresponding author (benitez@icmse.csic.es)

\begin{abstract}
To mimic non-toxic and fully biodegradable biopolymers like the plant cutin, polyester films from a natural occurring fatty polyhydroxyacid like aleuritic (9,10,16-trihydroxyhexadecanoic) acid have been prepared by non-catalyzed melt-polycondensation at moderate temperature $\left(150^{\circ} \mathrm{C}\right)$ directly in air. The course of the reaction has been followed by Infrared (IR) spectroscopy, ${ }^{13} \mathrm{C}$ Magic Angle Spinning Nuclear Magnetic Resonance $\left({ }^{13} \mathrm{C}-\mathrm{MAS}\right.$ NMR$)$ spectroscopy, Differential Scanning Calorimetry (DSC) and X-Ray Diffraction (XRD) and well differentiated stages are observed. First, a high conversion esterification reaction leads to an amorphous rubbery, infusible and insoluble material whose structure is made out of ester
\end{abstract}


linkages mostly involving primary hydroxyls and partially branched by minor esterification with secondary ones. Following the esterification stage, the cleavage of vicinal secondary hydroxyls and further oxidation to carboxylic acid is observed at the near surface region of films. New carboxylic groups created also undergo esterification and generate cross-linking points within the polymer structure. Additionally, and despite the harsh preparation conditions used, very little additional side reaction like per-oxidation and dehydration are observed. Results demonstrate the feasibility of polyester films fabrication from a reference fatty polyhydroxyacid like aleuritic acid by non-catalyzed melt-polycondensation directly in air. The methodology can potentially be extended to similar natural occurring hydroxyacids to obtain films and coatings to be used, for instance, as non-toxic and biodegradable food packaging material.

\section{INTRODUCTION}

Petrochemical derived plastics are commonly used in the packaging industry but they have raised serious concerns in the society due to their ecological impact. Particularly, in the case of metal food containers, the toxicity associated to the release of additives like bisphenol A from the internal protective coating is becoming a notorious health issue [1]. Polyesters constitute an important group of bioplastics intended to become an alternative. Thus, short chain polyesters like polylactic acid (PLA) and polyhydroxybutyrates (PHB) have received great attention in the past years. On the contrary, research on long-chain (fatty) polyhydroxyalcanoates is much more limited, mostly because the lack of effective routes to monomer synthesis. However, fatty polyhydroxyalcanoates are abundantly present in nature, for instance, as "cutin", the polyester skeleton of many plant cuticles (the skin of fruits, leaves and green stems) $[2,3]$. Cutin is an amorphous, non-toxic and fully biodegradable barrier biopolymer whose role is to protect plant tissues from the environment [4]. Precisely, good barrier capabilities as well as non-toxicity, availability and biodegradability are key features in the development of new food packaging materials. Consequently, the design and obtaining of polymers inspired in cutin is proposed as an option assuming that the synthetic product will retain the inherent characteristics of its natural counterpart $[5,6]$. 
Singularly, the biopolymer cutin is made out of a very limited series of esterified $\mathrm{C}_{16}$ and $\mathrm{C}_{18}$ hydroxyacids $[7,8,9]$. In this study, we have used a relatively abundant natural occurring $\mathrm{C}_{16}$ polyhydroxyacid like aleuritic (9,10,16-trihydroxyhexadecanoic) acid [10] as a model monomer because of its chemical similarity to others hydroxyacids present in natural cutins [11]. Also because of the potential that extra secondary hydroxyls acting as cross-linking points may add in a future development of the polymeric material. In any case, the ultimate purpose $o$ this research is to extend the conclusions to other natural occurring hydroxyacids or hydroxyacid mixtures that can be obtained, for instance, from the considerable amount of peel residues generated by the fruit processing industry.

On the other side, the polycondensation between carboxylic acids and alcohols or hydroxyacids is carried out in synthetic conditions using an organometallic catalyst and facilitating the removal of the water by-product (i.e. high temperature, reduced pressure, or adding an acidic hydrophilic agent) $[12,13,14]$. In this article, and to avoid the use of organic solvents, as well as heavy metal catalysts jeopardizing the non-toxicity of the final product, we propose the direct, non-catalyzed synthesis from molten monomers at moderate temperature. To our knowledge, there is only one literature reference reporting such a direct synthesis of a polyester from an $\mathrm{C}_{16}$ polyhydroxylated fatty acid under reduced pressure, though product characterization is limited [15]. Moreover, and to explore the potential of this methodology to the fabrication of low-cost and uniform films or coatings, we have carried out the synthesis directly in air without resorting to a reduced or inert atmosphere. The study will focus on the chemical monitoring of the reaction and in the characterization of the products obtained.

\section{EXPERIMENTAL}

Materials

Aleuritic (DL-threo-9,10,16-trihydroxyhexadecanoic, $\mathrm{C}_{16} \mathrm{H}_{32} \mathrm{O}_{5}$ ) acid (93.8\% by $\mathrm{NaOH}$ titration) was purchased from Fluka. The commercial product contains a significant amount of $\mathrm{NaCl}(\sim 6 \% \mathrm{w} / \mathrm{w})$ that was removed after washing with cold water. The absence of salt in the purified samples was checked by XRD. 


\section{Polymer synthesis}

Polyhydroxyesters were prepared by placing about $130 \mathrm{mg}$ of purified aleuritic acid in an open carbon doped Teflon mould (35 $\mathrm{mm} \times 10 \mathrm{~mm}$ and $0.5 \mathrm{~mm}$ deep) and heated in air inside an oven at $150^{\circ} \mathrm{C}$ for different periods of time (from $2 \mathrm{~h}$ up to $24 \mathrm{~h}$ ). After cooling at room temperature, rubbery films were pale yellow/green progressively turning into to light brown as heating time was increased. Their thickness was about $300 \mu \mathrm{m}$, as measured with a digital micrometer. Films used for XRD analysis were prepared from the original $\mathrm{NaCl}$ containing aleuritic acid to have an internal reference for quantification.

\section{Polymer characterization}

Transmission and Attenuated Total Reflected (ATR) Infrared Spectroscopy

Infrared data were collected in a FTIR spectrometer (FT/IR-6200, JASCO, Spain). For transmission measurements, $2 \mathrm{mg}$ of sample and $150 \mathrm{mg}$ of dry $\mathrm{KBr}$ were placed in an agate mortar with few drops of methanol. The mixture was grinded until homogenization and dried for $2 \mathrm{~h}$ at $50{ }^{\circ} \mathrm{C}$ to remove the methanol residue. A $10 \mathrm{~mm}$ diameter pellet was made using the whole mixture and spectra were acquired by accumulating 32 scans using a TGS detector operated at $4 \mathrm{~cm}^{-1}$ resolution.

ATR-FTIR infrared spectra were directly obtained from both sides of the films using a single reflection ATR accessory (MIRacle ATR, PIKE Technologies, USA) coupled to a liquid nitrogen cooled MCT detector. All spectra were recorded in the 4000 to $600 \mathrm{~cm}^{-1}$ range at $4 \mathrm{~cm}^{-}$

${ }^{1}$ resolution and accumulating 50 scans.

${ }^{13}$ C Magic Angle Spinning Nuclear Magnetic Resonance $\left({ }^{13} \mathrm{C} M A S-N M R\right)$

${ }^{13} \mathrm{C}$ Magic Angle Spinning Nuclear Magnetic Resonance $\left({ }^{13} \mathrm{C}\right.$ MAS-NMR) proton decoupling single-pulse spectra of polymers were obtained with a Bruker DRX400 spectrometer using a magnetic field of $9.36 \mathrm{~T}$ and equipped with a multinuclear probe. Due to sample insolubility, solid samples had to be used. Specimen were cut into small as possible pieces using a razor blade knife and packed in $4 \mathrm{~mm}$ zirconia rotors. Magic angle spinning was operated at $10 \mathrm{kHz}$. The spectra were acquired at a frequency of $100.61 \mathrm{MHz}$, using a $\pi / 6$ pulse width of 2.5 
$\mu$ s and a pulse space of $10 \mathrm{~s}$, which ensures nuclei full relaxation. In each run, 8500 spectra were accumulated. Compared to Cross Polarization Nuclear Magnetic Resonance (CP- NMR), the single-pulse method request much longer acquisition times (typically 24 hours) to register a spectrum with an acceptable signal-to-noise ratio but allows composition quantitative measurements from peak areas [16]. Chemical shifts are reported in ppm using tetramethylsilane as reference.

$X$-ray Diffraction $(X R D)$

XRD diffraction patterns were obtained with an X'Pert Pro (PANalytical) diffractometer using monochromated $\mathrm{CuK}_{\alpha}$ radiation and an $\mathrm{X}^{\prime} \mathrm{Celerator}$ detector with a $1 / 4^{\circ}$ fixed slit. The diffractograms were recorded between $3^{\circ}$ and $70^{\circ}(2 \theta)$ in $0.0501^{\circ}$ steps at $45 \mathrm{kV}$ and $40 \mathrm{~mA}$ and $200 \mathrm{~s}$ counting time. The films were placed on a zero background silicon single crystal plate adapting them to the goniometer in a $\theta-2 \theta$ configuration.

\section{Differential Scanning Calorimetry (DSC)}

DSC thermograms of polymers were acquired with a DSC Q20 (TA Instruments) from $70{ }^{\circ} \mathrm{C}$ to $150{ }^{\circ} \mathrm{C}$ under nitrogen flow $(50 \mathrm{~mL} / \mathrm{min})$ at $10{ }^{\circ} \mathrm{C} / \mathrm{min}$ using non-hermetic aluminum pans. Square pieces of the films were cut and accurately weighted (between 3.5 and $4.0 \mathrm{mg}$ ) and placed in good contact with the bottom of the pan. They were first cooled to $-70{ }^{\circ} \mathrm{C}$ and heated to $150^{\circ} \mathrm{C}$ and kept at this temperature for 2 minutes to eliminate residual moisture. Then, a cooling-heating cycle from $-70^{\circ} \mathrm{C}$ to $150^{\circ} \mathrm{C}$ was performed. The glass transition temperature $\left(T_{g}\right)$ was obtained from the second heating using the inflection method.

\section{Tensile Tests}

Tensile tests of films were measured using an MTS Criterion 42 machine equipped with a $10 \mathrm{~N}$ load cell and applying a $0.02 \mathrm{~N}$ preload. Rectangular uniform pieces $(7 \mathrm{~mm}$ x $20 \mathrm{~mm})$ and typically $300 \mu \mathrm{m}$ thick were cut and brought to rupture at a constant deformation rate of 0.2 
$\mathrm{mm} / \mathrm{min}$ at room environmental conditions. Stress values were calculated using the specimen cross-section under no applied load. The Young's modulus was obtained from the slope of the stress-strain curve within the first $1-4 \%$ relative elongation range using the built-in software. Experiments were repeated at least for 6 samples and parameters averaged to ensure reproducibility. After rupture, the bridge was returned to the starting position to check for macroscopic permanent deformations of samples.

\section{RESULTS}

Reaction progression

Time evolution of the non-catalyzed melt-condensation polymerization of aleuritic acid at $150^{\circ} \mathrm{C}$ in air has been monitored by transmission IR, Figure 1. Esterification is clearly stated by the progressive transformation of the $v_{\mathrm{C}=\mathrm{O}}$ of the acid at $1703 \mathrm{~cm}^{-1}$ into the characteristic band of esters at $1732 \mathrm{~cm}^{-1}$ and by the development of (C-O) stretchings in esters (OC-O-C) at $1176 \mathrm{~cm}^{-1}$ and $1245 \mathrm{~cm}^{-1}$ [17]. The reaction progression is also reflected in the modification and reduction of both the broad $v_{\mathrm{OH}}$ band around $3300-3450 \mathrm{~cm}^{-1}$ and the $v_{(\mathrm{C}-\mathrm{O})}$ of primary and secondary alcohols at $1052 \mathrm{~cm}^{-1}$ and $1071 \mathrm{~cm}^{-1}$, respectively. The stoichiometric excess of nonreacted hydroxyl groups causes the shoulder at $1715 \mathrm{~cm}^{-1}$ resulting from the perturbation of carbonyl groups of either acid or ester by hydrogen bonding.

The progression of the self-condensation of aleuritic acid has been analyzed by comparing the IR band areas of functional groups involved in the reaction $\left(\mathrm{A} v_{\mathrm{C}=\mathrm{O}} / \mathrm{A} v_{\mathrm{OH}}\right)$, Figure 2. If band areas $\left(\mathrm{A}_{\mathrm{i}}\right)$ are considered as the product between concentration of the active specie $\left(\mathrm{X}_{\mathrm{i}}\right)$ and a sensitivity factor $\left(\mathrm{S}_{\mathrm{i}}\right)$, at any time:

$$
\begin{aligned}
& \mathrm{A}_{\mathrm{vC}=\mathrm{O}}=\mathrm{S}_{\mathrm{CO}}\left(\mathrm{X}_{\mathrm{A}}+\mathrm{X}_{\mathrm{E}}\right) \\
& \mathrm{A}_{\mathrm{vOH}}=2 \mathrm{~S}_{\mathrm{OH}}\left(\mathrm{X}_{\mathrm{A}}+1\right)
\end{aligned}
$$

Where $\mathrm{X}_{\mathrm{A}}$ and $\mathrm{X}_{\mathrm{E}}$ are the actual molar fractions of acid and ester, respectively. The area ratio can be related to the extent of reaction (p):

$$
\mathrm{A}_{v \mathrm{C}=\mathrm{O}} / \mathrm{A}_{v \mathrm{OH}}=\mathrm{S}_{\mathrm{CO}} / 2 \mathrm{~S}_{\mathrm{OH}}(2-\mathrm{p})
$$

At the beginning of the reaction $(t=0)$ : 


$$
\left(\mathrm{A}_{v \mathrm{C}=\mathrm{O}} / \mathrm{A}_{v \mathrm{OH}}\right)_{0}=\mathrm{S}_{\mathrm{CO}} / 4 \mathrm{~S}_{\mathrm{OH}}
$$

And combining with Equation 3

$$
\mathrm{A}_{v \mathrm{C}=\mathrm{O}} / \mathrm{A}_{\mathrm{vOH}}=2\left(\mathrm{~A}_{\mathrm{vC}=\mathrm{O}} / \mathrm{A}_{\mathrm{vOH}}\right)_{0} /(2-\mathrm{p})
$$

Thus, the reaction progress $(p)$ can be calculated from the experimental $\left(\mathrm{A}_{\mathrm{vC}=\mathrm{O}} / \mathrm{A}_{\mathrm{vOH}}\right)$ ratios and values are plotted as an inset in Figure 2.

The evolution of the $\left(\mathrm{A}_{\mathrm{vC}=\mathrm{O}} / \mathrm{A}_{\mathrm{vOH}}\right)$ ratio suggests the occurrence of several stages. The first one is characterized by the growth and achievement of a steady value between 8-11 hours that is assigned to the condensation polymerization itself. Both, the low intensity of the free acid contribution $\left(\sim 1700 \mathrm{~cm}^{-1}\right)$ to the $v_{\mathrm{C}=\mathrm{O}}$ band in the plateau (Figure 1) and the achievement of the $\left(\mathrm{A}_{v \mathrm{C}=\mathrm{O}} / \mathrm{A}_{v \mathrm{OH}}\right)$ value corresponding to a polyester obtained in vacuum for $8 \mathrm{~h}$ at $150^{\circ} \mathrm{C}(0.29)$ suggests its completion, Figure 2. After the plateau, and in a second stage, the sudden increment of the $\mathrm{A} v_{\mathrm{C}=\mathrm{O}} / \mathrm{A} v_{\mathrm{OH}}$ ratio and a progressive increase after then are indications of additional reactions.

To better detect the chemical modifications involved in each stage, IR spectra have been subtracted between specific reaction times (Figure 2 (right)). Between 0 and 4 hours, negative bands at $1702 \mathrm{~cm}^{-1}$ and $3275 \mathrm{~cm}^{-1}$, as well as a positive peak at $1732 \mathrm{~cm}^{-1}$, are characteristic for the esterification between the carboxylic acid and the hydroxyl groups. The same modifications are observed between $4 \mathrm{~h}$ and $8 \mathrm{~h}$ (plateau), though the intensity has decreased appreciably as expected from the proximity to the reaction completion.

In the second stage, when IR spectra at the plateau and after $13 \mathrm{~h}$ reaction are compared, both: a strong increment of the $v_{\mathrm{C}=\mathrm{O}}$ absorption at $1743 \mathrm{~cm}^{-1}$ and an intense hydroxyl loss are observed. As the nominal esterification reaction is almost completed after $8 \mathrm{~h}$ at $150^{\circ} \mathrm{C}$, we ascribe these modifications to a vicinal diol cleavage and oxidation reaction in air forming new acid groups undergoing further esterification with surplus hydroxyls. Such vicinal diol cleavage reaction slows down as deduced from the difference after heating for additional 11 hours (from $13 \mathrm{~h}$ to $24 \mathrm{~h}$ ), Figure 2 (right). Additionally, minor amounts of other oxidation products can be detected after extended heating periods, among them peroxides (doublet around $1806 \mathrm{~cm}^{-1}$ and $1778 \mathrm{~cm}^{-1}$ ) and peroxyesters (R-CO-O-O-R', 1760-1770 $\mathrm{cm}^{-1}$ ) [18] contributing to the 
broadening on the high wavenumber side of the $v_{\mathrm{C}=\mathrm{O}}$ peak, Figure 1. Also, minor alcohol dehydration is detected by the $v_{(\mathrm{C}=\mathrm{C})}$ around $1630 \mathrm{~cm}^{-1}$.

The formation of the polyester within the first stage is corroborated by ${ }^{13} \mathrm{C}$ MAS-NMR, Figure 3. Evidences are the progressive transformation of the acid $(-\underline{\mathrm{COOH}}) 178.1 \mathrm{ppm}$ signal into the corresponding (- $\underline{\mathrm{CO}}-\mathrm{OR})$ at $174.3 \mathrm{ppm}$ and the appearance of aliphatic carbon signals at $33.7 \mathrm{ppm}\left(-\mathrm{C}_{2}-\mathrm{CO}-\mathrm{OR}\right)$ and $27.0 \mathrm{ppm}\left(-\mathrm{CH}_{2}-\mathrm{CO}-\mathrm{O}-\mathrm{CH}_{2}-\mathrm{CH}_{2}-\right)$. Moreover, primary hydroxyl esterification is confirmed by the transformation of the $62.7 \mathrm{ppm}$ peak $\left(\mathrm{HO}-\underline{\mathrm{C}} \mathrm{H}_{2}-\right)$ into the one at $65.3 \mathrm{ppm}\left(-\mathrm{CH}_{2}-\mathrm{CO}-\mathrm{O}-\mathrm{CH}_{2^{-}}\right)[19,20,21,22,23]$. Once the polyester is formed $(11 \mathrm{~h}),{ }^{13} \mathrm{C}$ MAS-NMR reveals the presence of both free $(62.7 \mathrm{ppm})$ and esterified (65.3 ppm) primary hydroxyls and their band area ratio indicate that most of them have reacted (about 75 to $80 \%$ ). Consequently, esterification of secondary hydroxyls has to be much more reduced. Indeed, minor secondary hydroxyl esterification can be postulated from the weak component around 8283 ppm (- $\underline{C}$ HOR-CHOH-) in the ${ }^{13} \mathrm{C}$ MAS-NMR spectra.

The vicinal diol cleavage and oxidation reaction in air is also detected by ${ }^{13} \mathrm{C}$ MASNMR. As observed above $11 \mathrm{~h}$ in Figure 3, there is a slight enhancement of the intensity of the carbonyl ( $\sim 175 \mathrm{ppm})$ signal accompanied by a decrease of the secondary hydroxyl peak $(\sim 75$ ppm). Additionally, such formation of new carboxylic groups is detected by means of a residual non-esterified fraction causing the small sharp peak at $176.8 \mathrm{ppm}$.

\section{Structural Characterization}

XRD patterns of polyester films prepared by non-catalyzed melt-polycondensation of aleuritic acid at $150^{\circ} \mathrm{C}$ in air at different reaction times are shown in Figure 4A. Solids obtained at the plateau and above display a single broad peak at $19.7^{\circ}$ characterizing amorphous aliphatic polymers. Earlier peaks at $8.4^{\circ}, 19.5^{\circ}$ and $22.6^{\circ}$ are assigned to the non-reacted aleuritic acid phase. Their disappearance after 12-13 hours reaction agrees with the reaction completion indicated by the plateau defined from IR data in Figure 2.

The initial first heating DSC thermogram (not shown) of the polymeric films contains an endothermic peak around $46^{\circ} \mathrm{C}$ whose intensity continuously decreases until disappearance 
above $12 \mathrm{~h}$ reaction. In good agreement with IR and XRD data, this endothermic event is associated to the melting of a metastable phase of the non-reacted aleuritic acid fraction (aleuritic acid m.p. $94^{\circ} \mathrm{C}$ ). Figure 4B (inset) displays the DSC second heating cycle of the series showing the crystallization-melting event of the metastable acid phase as well as the glass transition $\left(T_{g}\right)$ assigned to the amorphous polyester phase created. The glass transition is observed to linearly shift to higher temperature as the esterification reaction proceeds and up to the acid phase depletion after $12-13 \mathrm{~h}$ reaction at $150{ }^{\circ} \mathrm{C}$, Figure $4 \mathrm{~B}$.

The polyesters obtained show a good thermal stability as indicated by maximum thermal degradation rate peaks $\left(T_{d(\max )}\right)$ around $450^{\circ} \mathrm{C}$.

Tensile tests data of the series of polyhydroxyesteres prepared are compiled in Figure 5. In every case, the curves correspond to a viscoelastic behavior showing no strain softening. After rupture, no appreciable macroscopic permanent deformation are observed. The Young's modulus displays two patterns within the series. First (below $11 \mathrm{~h}$ preparation), there is a continuous decrease that is related to the consumption of the crystalline aleuritic acid phase. In this stage, the polymer can be elongated up to $30 \%$ before breaking. Full elimination of the acid is characterized by a sudden elastic modulus fall and a notorious increment of the strain at break (up to $70 \%$ ). The second stage (above $11 \mathrm{~h}$ reaction) shows a very smooth elastic modulus increment accompanied by a strong reduction of the elongation at break.

\section{DISCUSSION}

The kinetics of the thermal self-polymerization of aleuritic acid has been previously studied by determination of acid and saponification values by titration [15]. In this article we monitor the process by the analysis of the IR absorptions of the functional groups (- $\mathrm{C}=\mathrm{O}$ and $\mathrm{OH})$ involved in the esterification reaction. $\mathrm{A} v_{\mathrm{C}=\mathrm{O}} / \mathrm{A} v_{\mathrm{OH}}$ ratios indicate that despite the atypical synthesis conditions used, i.e. no catalyst and no hydrophilic phase or reduced pressure to trap water molecules, the self-polycondensation of aleuritic acid in air at $150{ }^{\circ} \mathrm{C}$ reaches a final conversion of about $94 \%$ in 7-8 hours. As a reference, a similar conversion (98\%) has been calculated by thermogravimetry from the water evolved after heating aleuritic acid under $\mathrm{N}_{2}$ for 
$8 \mathrm{~h}$ at $150{ }^{\circ} \mathrm{C}$. Moreover, spectroscopic IR and ${ }^{13} \mathrm{C}$ MAS-NMR data (Figures 1 and 3), as well as the similarity with the IR spectrum of samples prepared under vacuum (Figure S1), confirm the high purity and the absence of side oxidation reactions within this first esterification stage. Furthermore, the elemental analysis $(\mathrm{w} / \mathrm{w})$ of the polymer obtained after $8 \mathrm{~h}$ reaction is $67.4 \%$ (C), $9.9 \%(\mathrm{H})$ and $22.7 \%(\mathrm{O})$ in quite good agreement with the theoretical values $67.1 \%(\mathrm{C})$, $10.5 \%(\mathrm{H})$ and $22.4 \%(\mathrm{O})$.

In this esterification stage, XRD and DSC data show the progressive consumption of the crystalline acid phase but discard the formation of a fusible polyhydroxyester from aleuritic acid as observed for alike $\omega$-hydroxyacids [14,23]. The same conclusion is obtained from the absence of the characteristic series of bands in the $1300-700 \mathrm{~cm}^{-1}$ range in crystalline polyesters [24], Figure 1. The elimination of the acid phase is also reflected in the tensile properties of the polycondensation product. Thus, Figure 5 shows a continuous increment of elasticity that is correlated (upper inset) with the reduction of the acid phase as determined from XRD. Here, aleuritic acid crystallites are proposed to act as rigid fillers in the amorphous rubbery phase increasing the Young's modulus and reducing the strain at break.

As deduced from the ratio between primary $\left(1051 \mathrm{~cm}^{-1}\right)$ and secondary $\left(1072 \mathrm{~cm}^{-1}\right)$ hydroxyl IR intensities, Figure 1, and the quantification of the carbonyl and hydroxyl ${ }^{13} \mathrm{C}$ MASNMR signals, Figure 3, and despite secondary hydroxyl excess, esterification is more extended with primary hydroxyl groups. Minor esterification of secondary hydroxyls gives rise to branching but no covalent cross-linking is possible at the esterification stage.

On the other side, the polyhydroxyester formed is infusible and quite insoluble in a wide series of pure and mixed solvents, among them chloroform, toluene, light alcohols, THF, DMF and DMSO, which, in turn, impeded molecular weight determination. However, DSC reveals a linear increment of $T_{g}$ with heating time within the esterification stage, Figure 4B. Assuming a Flory-Fox type relationship between $T_{g}$ and the number-average molecular weight (M):

$$
T_{g}=T_{g, \infty}-K / M
$$

The molecular number-average molecular weight can be related to the heating time ( $\mathrm{t}$ ) by the equation: 


$$
M=K /\left(T_{g, \infty}-T_{g, 0}-\alpha t\right)
$$

Where $K$ is an empirical constant, $T_{g, \infty}$ and $T_{g, 0}$ the glass transition temperature at reaction times $t=\infty$ and $t=0$, respectively, and $\alpha$ the slope of the linear part of $T_{g}$ vs $t$ relationship observed in Figure 4B. Unfortunately, the value of $K$ cannot be determined and therefore not even an estimation of the number-average molecular weight of the polyesters obtained can be provided. However, Equation 7 predicts an asymptotic molecular weight increase with heating time as interpreted from a successive aggregation of partially branched moieties into larger structures up to tentative gelation. Thus, the structure of the final polyhydroxyester could be described as a three dimensional primary ester-bonded network with partial branching arising from the esterification of secondary hydroxyls. This primary structure is completed by a secondary network of hydrogen bonded hydroxyls but no covalent cross-linking at this stage can be stated from our experimental data.

In a second stage, and following the esterification, IR and ${ }^{13} \mathrm{C}$ MAS-NMR data reveal the reduction of secondary hydroxyls and the simultaneous increment of carbonyl species. This is interpreted as the occurrence of a thermal diol cleavage and oxidation reaction in air:

$$
\mathrm{R}-\mathrm{CH}_{2}(\mathrm{OH})-(\mathrm{OH}) \mathrm{H}_{2} \mathrm{C}-\mathrm{R}^{\prime}+2 \mathrm{O}_{2} \rightarrow \mathrm{R}-\mathrm{COOH}+\text { HOOC-R' }+2 \mathrm{H}_{2} \mathrm{O}
$$

From the $\mathrm{A}_{v \mathrm{C}=\mathrm{O}} / \mathrm{A}_{\mathrm{vOH}}$ values in Figure 2, about $13 \%$ of monomers are calculated to undergo this cleavage reaction by heating from $10 \mathrm{~h}$ to $13 \mathrm{~h}$. Surprisingly, such reaction is not evidenced until full consumption of the acid phase and infusibility are achieved. Therefore, we postulate a gas-solid reaction at the near surface of the polyhydroxyester as deduced from ATR-FTIR data of the air-exposed side of the film (Figure S2). The fact that the reaction slows down as heating continues, Figure 2, indicates that its progression is controlled by the slow oxygen diffusion into the film bulk.

Spectroscopic data also reveals that new carboxylic acid groups generated in the diol cleavage and oxidation reaction also undergo esterification with the excess of secondary hydroxyls giving rise to a small amount of cross-linking (two new ester linkages per C-C cleaved). An experimental indication of such cross-linking is the enhancement of the $82 \mathrm{ppm}$ 
${ }^{13}$ C MAS-NMR signal corresponding to esterified secondary hydroxyls, Figure 3. Cross-linking is then associated to the diol cleavage and oxidation reaction that has been proved to be restricted to the near surface region of the air exposed side of the film. For this reason, bulk parameters such as the $T_{g}$ and the Young's modulus grow slightly in the second stage. However, strain at break is strongly affected, Figure 5. Our hypothesis is that fracture is better initiated and propagated in the altered face of the films leading to appreciably smaller rupture elongations.

Tensile parameters of poly(aleuritate) are well below of those of others polyesters like $\operatorname{poly}(\varepsilon$-caprolactone $)$ and medium and long-chain poly ( $\omega$-hydroxyfatty acids) $[14,25,26]$. Thus, the Young's modulus and the stress at break can be up to 100 and 10 times smaller, respectively. This is an important feature conditioning the final uses of this polymer. However, the availability of free hydroxyls in the structure of the polyhydroxyester is considered as centers for the action of cross-linkers improving the mechanical behavior of the base polymer. Moreover, and compared to such poly ( $\omega$-hydroxyfatty acids), poly(aleuritate) has two important features: infusibility and insolubility, which in turn makes processing more complex. However, they are of great interest, for instance, in designing coating resins for metal food containers. The formation of coatings few micron thick will undoubtedly reduce the synthesis time reported here of few hundred micron thick films making the process to be more efficient.

As potential food preserving coating, the barrier properties of poly(aleuritate) films are currently being investigated by our group. They are proven to be hydrophobic displaying high water contact angle $\left(95-100^{\circ}\right)$ and low water absorption $(\sim 3 \% \mathrm{w} / \mathrm{w})$ and permeance $\left(\sim 2 \times 10^{-5}\right.$ $\left.\mathrm{m} \mathrm{s}^{-1}\right)$.

Another important aspect launching the obtaining of polyesters from natural occurring fatty acids is their presumable non-toxicity and biodegradability based on the chemical similarity with biopolyesters like cutin. Our preliminary results show that poly(aleuritate) is slowly degraded in contact with soil by both chemical hydrolysis and by the action of microorganism like fusarium fungi. 


\section{CONCLUSIONS}

Experimental data presented in this article show that few hundred micron thick polyhydroxyester films can be directly prepared by non-catalyzed melt-condensation polymerization in air from a natural occurring fatty hydroxyacid like aleuritic $(9,10,16$ trihydroxyhexadecanoic) acid. The esterification reaction has been clearly stated from spectroscopic data and it is characterized by the high conversion obtaining of an amorphous, insoluble and infusible rubbery elastic material showing a quite low Young's modulus and a considerable elongation with no permanent deformation after tensile rupture. The structure of the polymer consists of a primary ester-bonded framework, mostly involving primary hydroxyls, and partially branched by esterification with secondary ones. The main network is completed by hydrogen bonding interactions between free secondary surplus hydroxyls.

After the polyhydroxyester is formed and upon further heating, oxidation and dehydration side reactions have been observed at the near surface region. Oxidative degradation forms additional carboxylic acid groups undergoing esterification and causing a small amount of covalent cross-linking having little influence on bulk parameters such as the glass transition temperature and the Young's modulus.

Results obtained in this study can be extended to the design of non-toxic and biodegradable films or coatings for food packaging from similar natural occurring fatty hydroxyacids that can be extracted, for instance, from peel residues in the fruit processing industry.

\section{ACKNOWLEDGEMENTS}

Funding is provided by the Spanish Ministerio de Economía y Competitividad, project CTQ2011-24299, and by Junta de Andalucía grant TEP-7418 under the Motriz Program. 


\section{References}

[1] NPT-CERHR Monograph on the Potential Human Reproductive and Developmental Effects of Bisphenol A, Center for the Evaluation of Risks to Human Reproduction, US Department of Health and Human Services, pub. No. 08-5994 (2008).

[2] Pollard, M.; Beisson, F.; Li, Y.H.; Ohlrogge, J.B. Trends Plant Sci 2008, 13, 236.

[3] Heredia, A. Biochim Biophys Acta 2003, 1620, 1.

[4] Domínguez, E.; Heredia-Guerrero, J.A.; Heredia, A. New Phyt 2011, 189, 938.

[5] Benítez, J.J.; García-Segura, R.; Heredia, A. Biochim Biophys 2004, 1674, 1.

[6] Heredia-Guerrero, J.A.; Heredia, A.; García-Segura, R.; Benítez, J.J. Polymer 2009, 50, 5633.

[7] Walton, T.J. Methods Plant Biochem 1990, 4, 105.

[8] Baker, E.A.; Holloway, P.J. Phytochemistry 1970, 9, 1557.

[9] Kolattukudy, P.E. Ann Rev Plant Physiol 1981, 32, 539.

[10] Berger, S.; Sicker, D. in "Classics in Spectroscopy. Isolation and Structure Elucidation of Natural Products", Chapter 6. Wiley-VCH Verlag GmbH \& Co. KGaA, Weinheim (2009).

[11] Arrieta-Baez, D.; Cruz-Carrillo, M.; Gómez-Patiño, M.B.; Zepeda-Vallejo, L.G. Molecules 2011, 16, 4923.

[12] Bawn, C.E.H.; Huglin, M.B. Polymer 1962, 3, 257.

[13] Saam, J.C. J Polym Sci Part A: Polym Chem 1998, 36, 341.

[14] Liu, C.; Liu, F.; Cai, J.; Xie, W.; Long, T.E.; Turner, S.R.; Lyons, A.; Gross, R.A. Biomacromolecules 2011, 12, 3291.

[15] Zahurul Haque, M.; Omar Faruq, M. J Bangladesh Acad Sci 2000, 24, 171.

[16] Massiot, D.; Fayon, F.; Capron, M.; King, I.; Le Calvé, S.; Alonso, B.; Durand, J.O.;

Bujoli, B.; Gan, Z.; Hoatson, G. Mag Res Chem 2002, 40, 70.

[17] Bellamy, L J. in "The Infrared Spectra of Complex Molecules", vol 1. John Wiley and Sons, New York (1975).

[18] Davison, W.H.T. J Chem Soc 1951, 2456. 
[19] Pretsch, E.; Simon, W.; Seibl, J.; Clerc, T. in "Tables of Spectral Data for Structure Determination of Organic Compounds. Springer-Verlag, Berlin Heidelberg (1989).

[20] Zlotnik-Mazori, T.; Stark, R.E. Macromolecules 1988, 21, 2412.

[21] Ahmed, A.; Crawford, T.; Gould, S.; Ha, Y.S.; Hollrah, M.; Noor-E-Ain, F.; Dickman, M.B.; Dussault, P.H. Phytochemistry 2003, 63, 47.

[22] Deshmukh, A.P.; Simpson, A.J.; Hatcher, P.G. Phytochemistry 2003, 64, 1163.

[23] Pandey, A.K.; Nande, S.S.; Selukar, B.S.; Garnaik, B. e-Polymers 2010, 131, 1.

[24] Davison, W.H.T.; Corish, P.J. J. Chem. Soc. 1955, 2428.

[25] Engelberg, I.; Kohn, J. Biomaterials 1991, 12, 292.

[26] Jose, J.; Li, S.; Bouzidi, L.; Leao, A. L.; Narine, S. S. J. Appl. Polym Sci 2014, 40492. 
John Wiley \& Sons, Inc. 


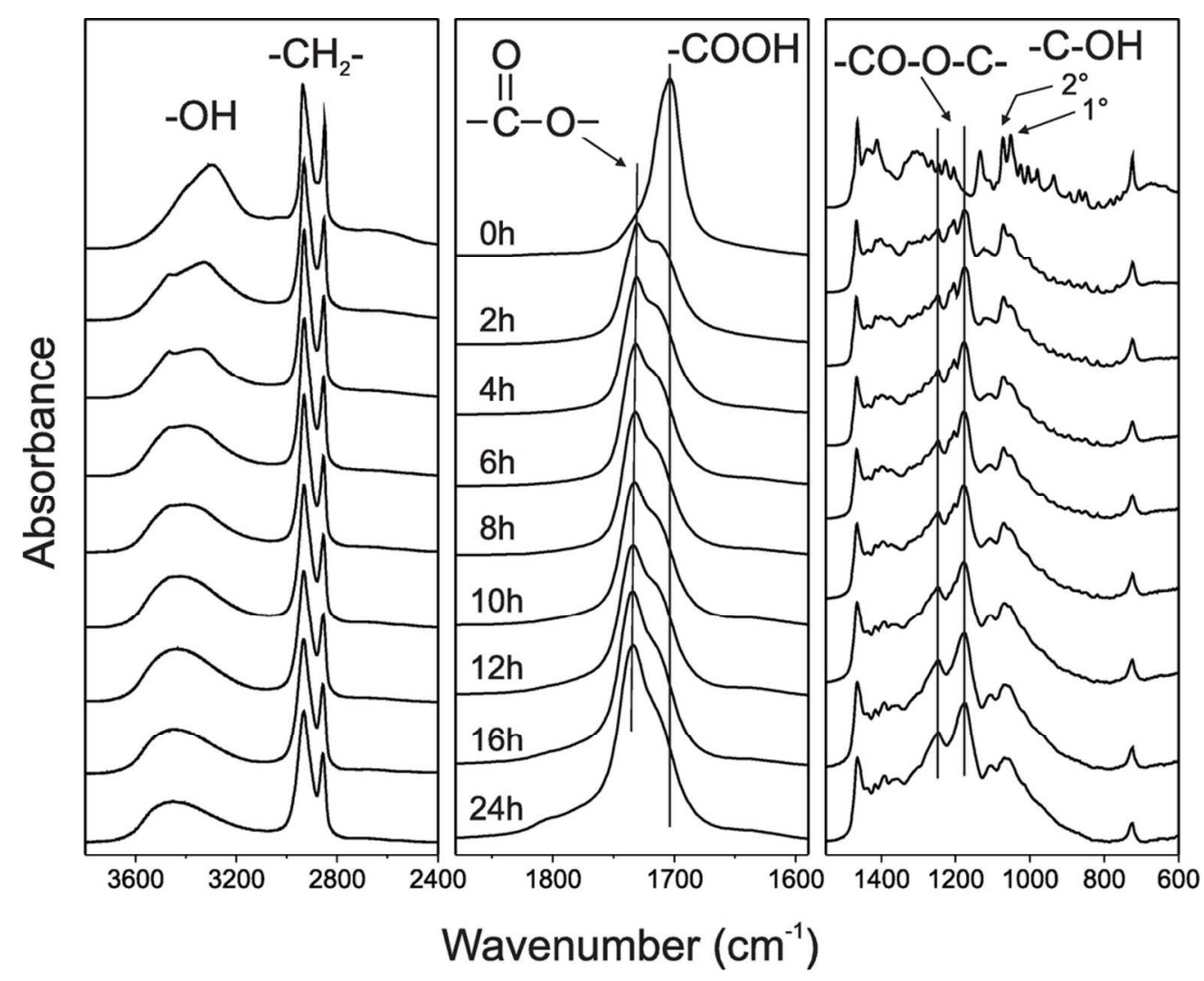

Infrared transmission spectra of the products resulting from the non-catalyzed melt-polycondensation of aleuritic acid at $150^{\circ} \mathrm{C}$ in air after reacting for the indicated times. Spectra are normalized to the area of $\mathrm{v}(-$ CH2-) peaks between 2800-2900 cm-1.

$92 \times 74 \mathrm{~mm}(300 \times 300 \mathrm{DPI})$ 

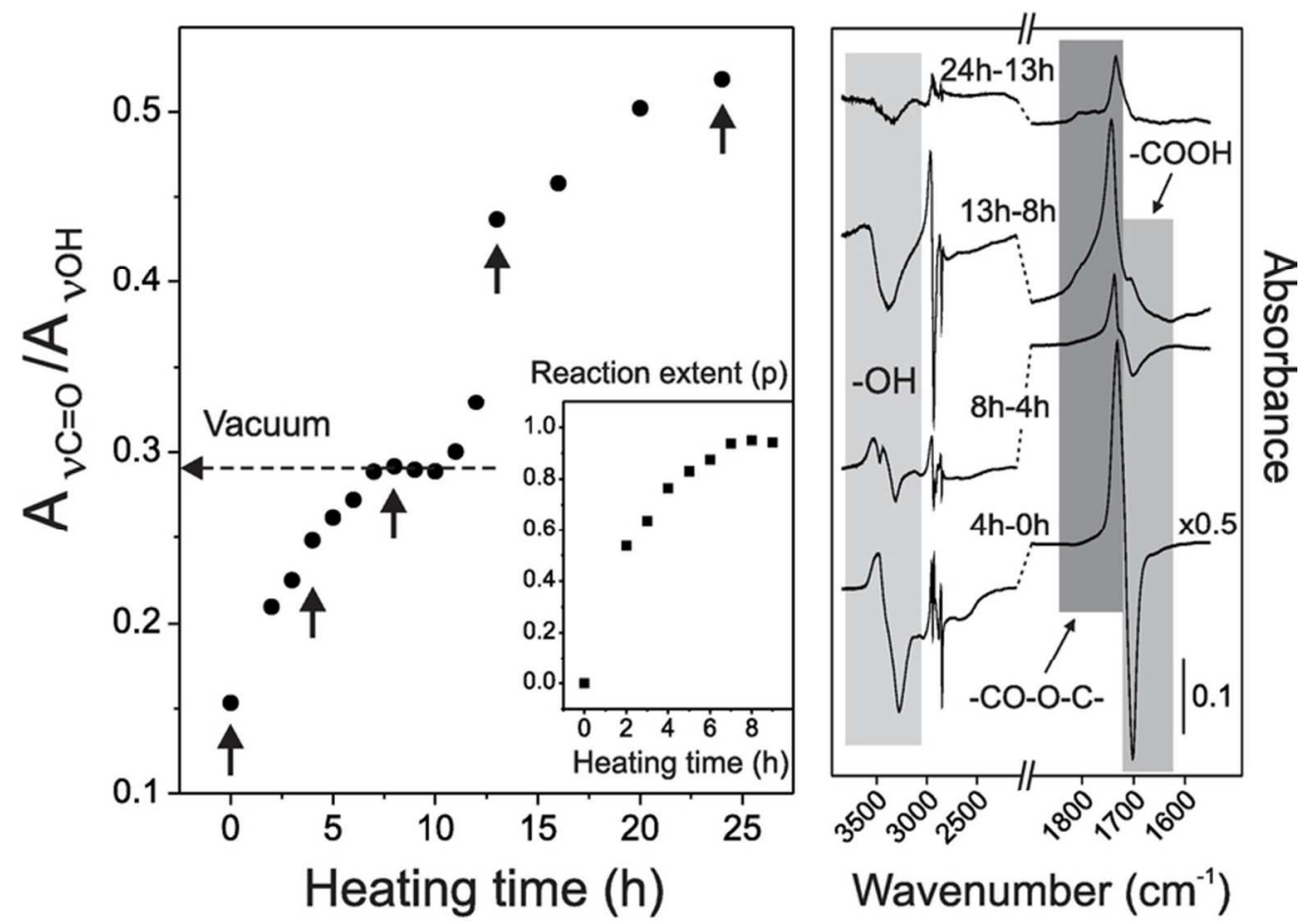

(left) Evolution of the area ratio between carbonyl and hydroxyl IR stretching bands vs reaction time (circles) in the non-catalyzed melt-polycondensation of aleuritic acid at $150^{\circ} \mathrm{C}$ in air. As a reference, the $(\mathrm{AvC}=\mathrm{O} / \mathrm{AvOH})$ obtained for a sample prepared under vacuum is included. The inset in the lower part shows the extent of reaction $(p)$ vs reaction time as calculated from the $(\mathrm{AvC}=\mathrm{O} / \mathrm{AvOH})$ values. (right) IR spectra differences highlighting the chemical modifications occurred between specific reaction times. $72 \times 51 \mathrm{~mm}(300 \times 300 \mathrm{DPI})$ 


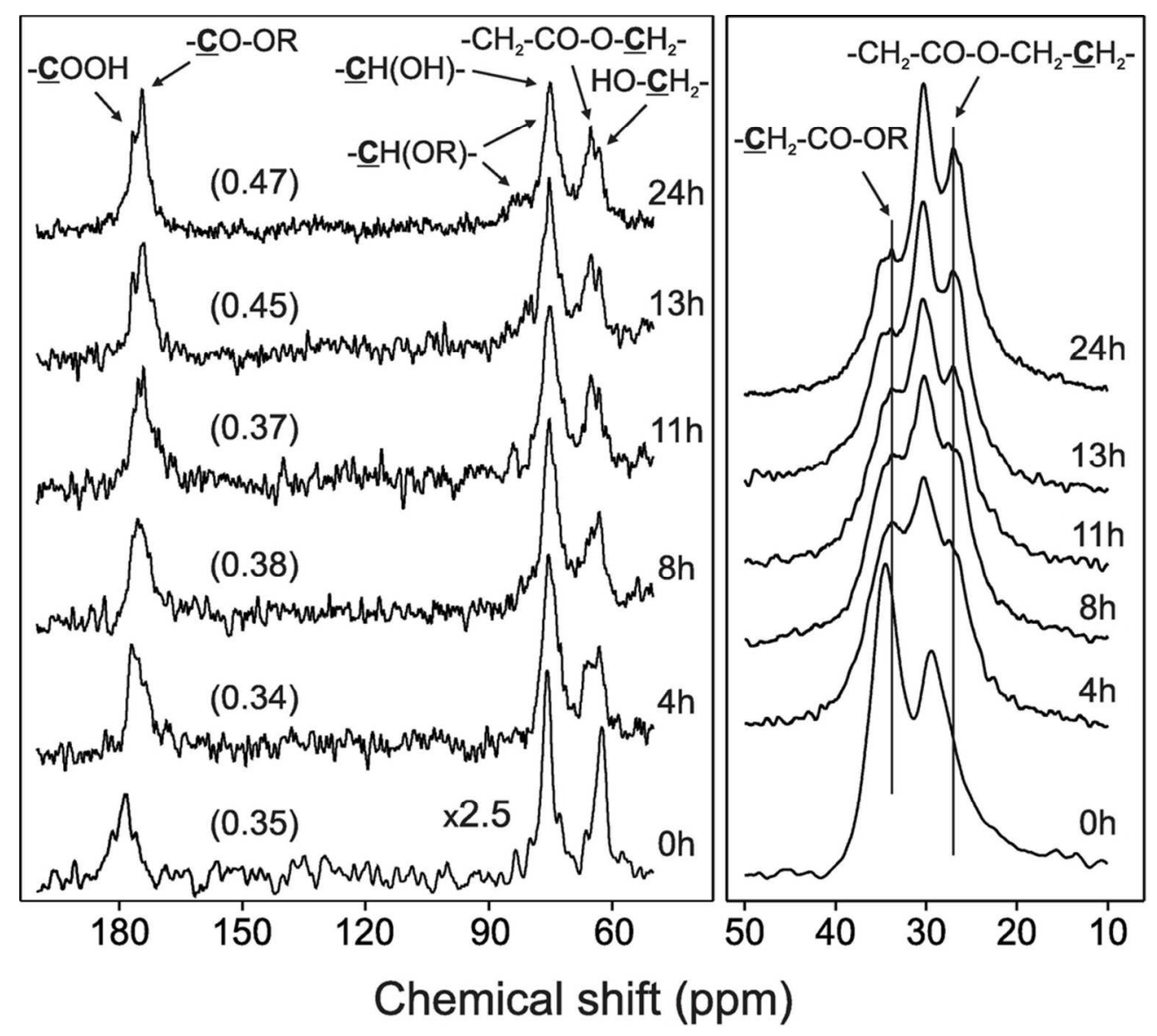

${ }^{13} \mathrm{C}$ MAS-NMR proton decoupling single-pulse spectra of samples obtained after indicated reaction times in the non-catalyzed melt-polycondensation of aleuritic acid at $150{ }^{\circ} \mathrm{C}$. For clarity, the $50-200$ ppm region intensity is expanded by a factor of 2.5 . Area ratio between $(C=O)$ and $(C-O)$ signals are indicated between parentheses.

$93 \times 82 \mathrm{~mm}(300 \times 300$ DPI $)$ 

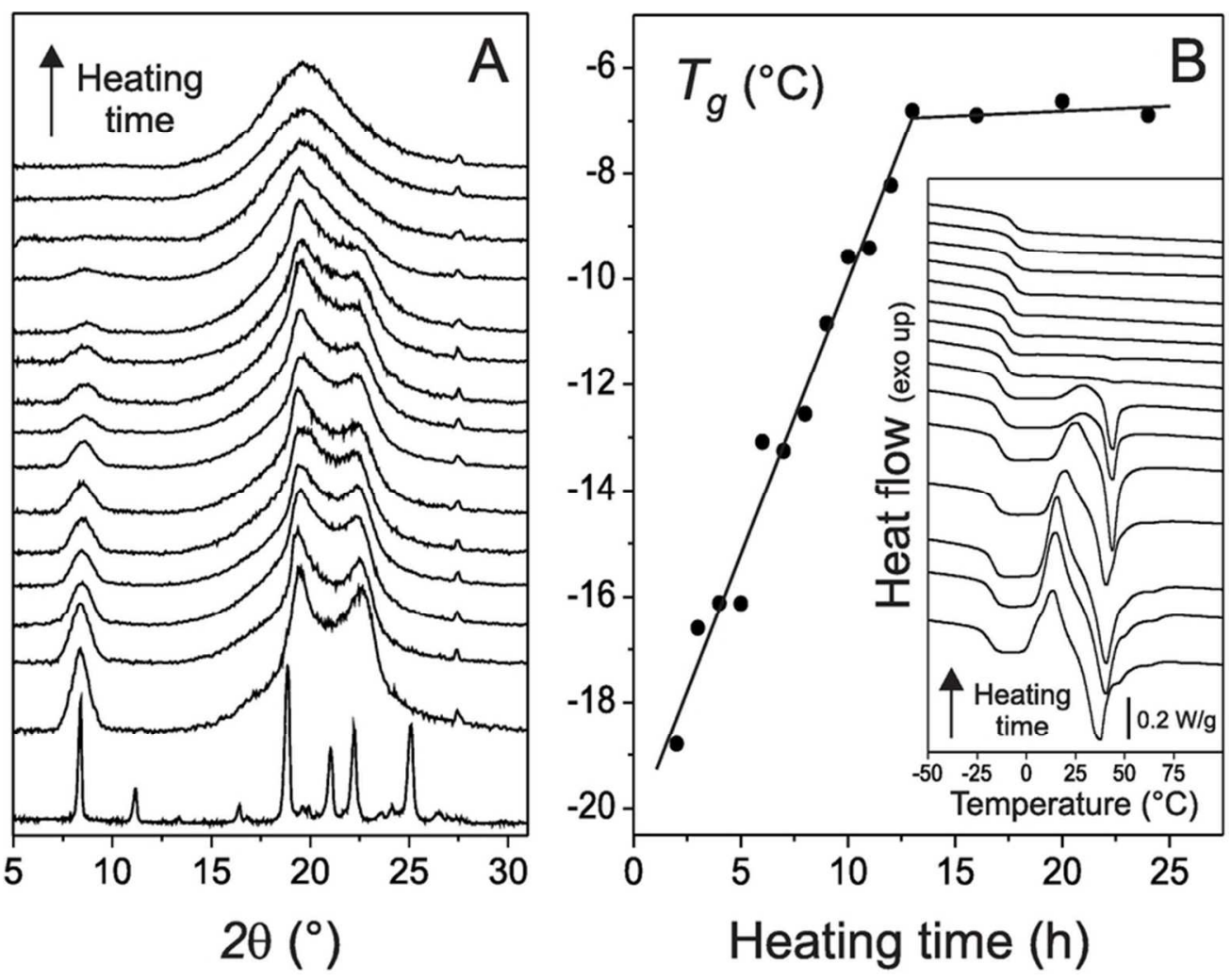

(A) XRD patterns of samples prepared by non-catalyzed melt-polycondensation of aleuritic acid at $150{ }^{\circ} \mathrm{C}$ in air after reacting for (down to up) $0,2,3,4,5,6,7,8,9,10,11,12,13,16,20$ and 24 hours, respectively. (B) Glass transition temperature $\left(T_{g}\right)$ evolution vs reaction time, (inset) DSC thermograms (second heating) of samples indicated in (A).

$73 \times 57 \mathrm{~mm}(300 \times 300$ DPI $)$ 


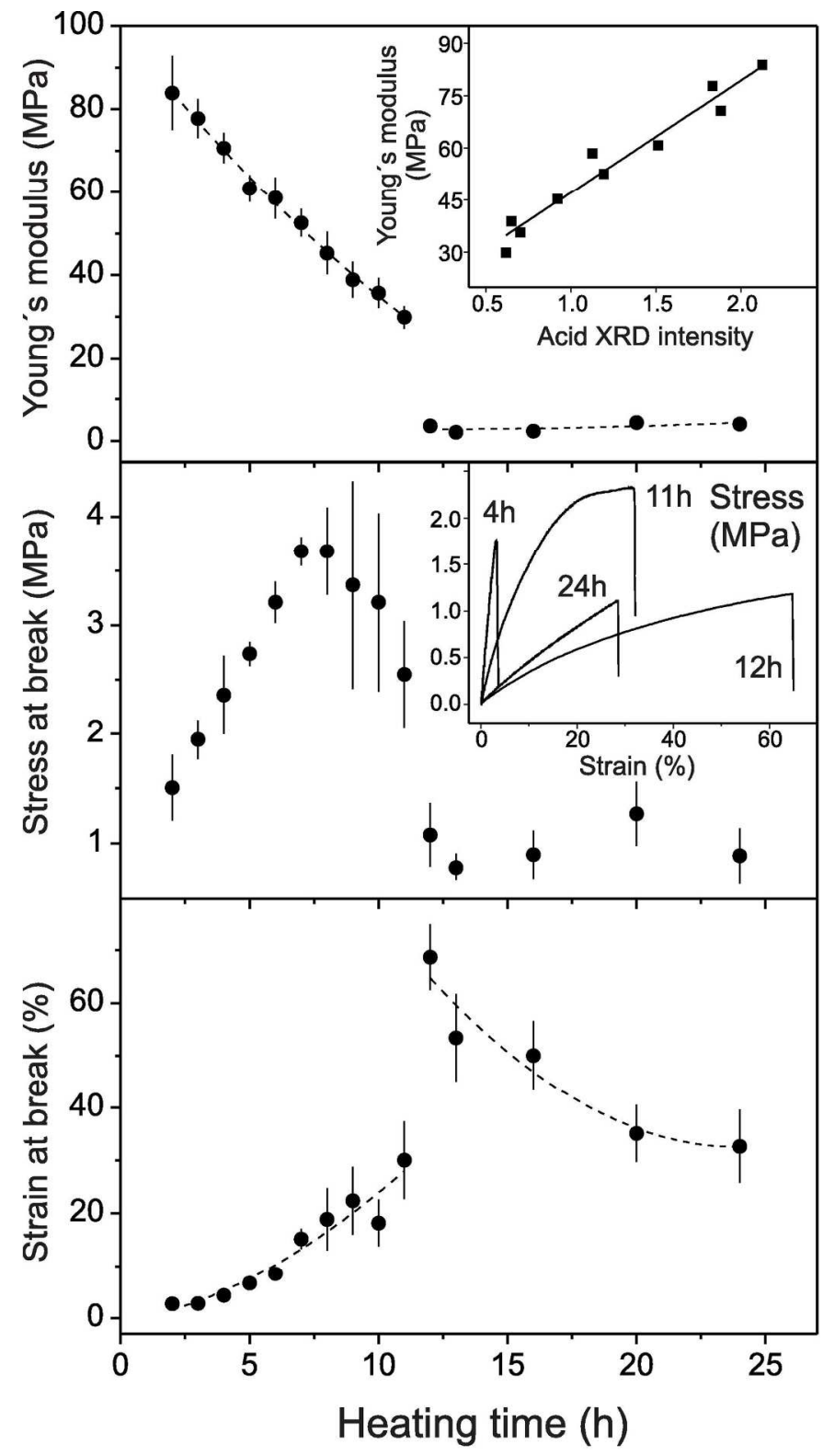

Tensile parameters of films prepared by non-catalyzed melt-polycondensation of aleuritic acid at $150{ }^{\circ} \mathrm{C}$ in air at different reaction times. The upper inset shows the relationship between the Young 's modulus and the presence of non-reacted aleuritic acid phase. The lower inset displays typical stress-strain curves at selected reaction times.

$135 \times 244 \mathrm{~mm}(300 \times 300 \mathrm{DPI})$ 